\title{
La inundación en el sur de la cuenca de México a través de la imagen cartográfica (I866-1869)
}

N I865 OCURRIó unA MEMORABLE inundación en la ciudad de México. En ese momento gobernaba Maximiliano de Habsburgo y tuvo que enfrentar la inestabilidad social y el conflicto que significó una ciudad anegada. Las inundaciones en la capital mexicana eran recurrentes, pero la experiencia de 1865 obligó a tomar medidas inmediatas; como consecuencia se llevaron a cabo una serie de acciones para las obras del desagüe; el documento que se analizará en este ensayo es una representación de este acontecimiento. Se trata de la imagen de un territorio anegado que lleva por título Plano general del terreno que comprende las obras del desagüe ejecutadas en el sur del valle de México, por disposición del señor ingeniero, director de las aguas, don Francisco de Garay; bajo la dirección inmediata del ingeniero encargado de las obras en dicha sección (fig. I) y fue realizado en diciembre de I866. El plano de Garay posee características que lo hacen notable: la calidad del dibujo y el color permiten apreciar un diseño cartográfico de la época; la temática que aborda (la inundación) da oportunidad de tratar de forma clara una situación que se expone con frecuencia en los planos de aquel momento; finalmente, el ingeniero Francisco de Garay fue un personaje que participó en proyectos y 


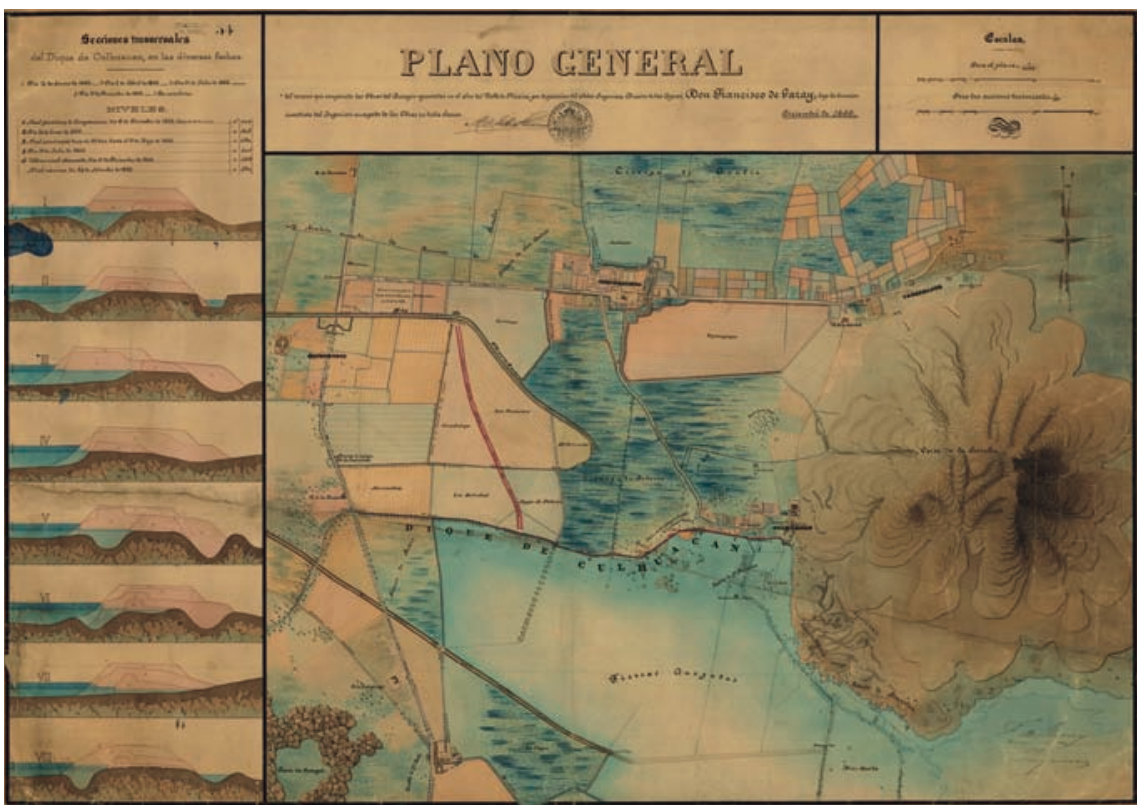

I. Francisco de Garay, Plano general del terreno que comprende las obras del desagüe ejecutadas en el sur del valle de México, por disposición del señor ingeniero, director de las aguas, don Francisco de Garay; bajo la dirección inmediata del ingeniero encargado de las obras en dicha sección, diciembre de I866. México, Mapoteca Manuel Orozco y Berra, Servicio de Información Agroalimentaria y Pesquera, SAGARPA, núm. 655-50.

obras de ingeniería hidráulica sobre la capital y que también desempeñó cargos administrativos, por lo cual, al igual que con la pieza aquí expuesta, es posible hacer la comparación con sus similares.

Se analizará el Plano general del terreno que comprende las obras del desagüe ejecutadas en el sur del valle de México... con el objetivo de estudiar los planos como dispositivos visuales específicos a partir de los cuales se aprehende el área de la cuenca de México, en este caso, un fragmento de ella. Para acercarse al objeto, será preciso comprender e identificar el lenguaje propio de la disciplina cartográfica expresado en la carta (compuesto por los elementos que vierten información en forma de convenciones) y esto conducirá a la referencia de las ingenierías como campo profesional dentro del cual se consolida la producción de planos; como consecuencia se hará hincapié en los ingenieros en tanto actores que fabrican tales representaciones del territorio y que también, 
muchas veces, ordenan su ejecución. Así pues, otro de los objetivos será la referencia a los mismos planos como instrumentos de la ingeniería y la política.

La cartografía no fue el único medio gráfico con que se expresó la inundación (hay testimonios en caricatura, escultura ${ }^{\mathrm{I}}$ y fotografía) y por tanto se recurrirá a otros soportes como apoyo, pero la intención central consiste en construir un plano como una imagen que brinda una perspectiva particular en un momento y en una situación concretos; este documento arrojará información valiosa sobre la cultura visual que lo hace surgir, entrelazando ámbitos y personajes. Se trata, en fin, de valorar un tipo de representación del territorio argumentando sobre su especificidad.

\section{Descripción de la cuenca}

La ciudad de México se fundó en una cuenca y está rodeada al sur, al oriente y al poniente por cordilleras volcánicas y al norte por colinas y cordilleras bajas. El terreno más bajo de la cavidad fue una planicie lacustre (el lago de Texcoco), por lo que es correcto referirnos al terreno natural sobre el cual se estableció la capital como una formación hidrológica cerrada. Además de la laguna de Texcoco, había un complejo sistema hidráulico natural compuesto por una cadena de lagos poco profundos: en el norte los de Zumpango, Xaltocan y San Cristóbal y en el sur los de Chalco y Xochimilco; todos ellos se encontraban a mayor altitud que la laguna de Texcoco, por lo cual ésta cumplía la función de un vaso que recogía los derrames de los demás (fig. 2).

La cercanía de la ciudad de México con el vaso de Texcoco y el hecho de estar rodeada de elevaciones fueron causa de recurrentes inundaciones; ${ }^{2}$ durante la temporada de lluvias, de mayo a agosto, el nivel de la laguna subía amenazando a la capital; aun cuando en la ciudad no lloviera copiosamente, si al norte o al sur había precipitaciones, el vaso se iba llenando.

Ciertamente hubo años en que las lluvias fueron memorables; uno de ellos fue I 865 . Ese año se prolongaron excepcionales aguaceros y el sistema lacustre

I. Véase Citlali Salazar Torres, "Una ciudad sitiada. El monumento hipsográfico de la ciudad de México I877-I88I", tesis para obtener el grado de maestra en Historia del Arte, México, Universidad Nacional Autónoma de México-Facultad de Filosofía y Letras, 2008.

2. Véase Peter Krieger, “Acuápolis. Temas y problemas”, en Peter Krieger (ed.), Acuápolis, México, Universidad Nacional Autónoma de México-Instituto de Investigaciones Estéticas, 2007, pp. 17-94. 


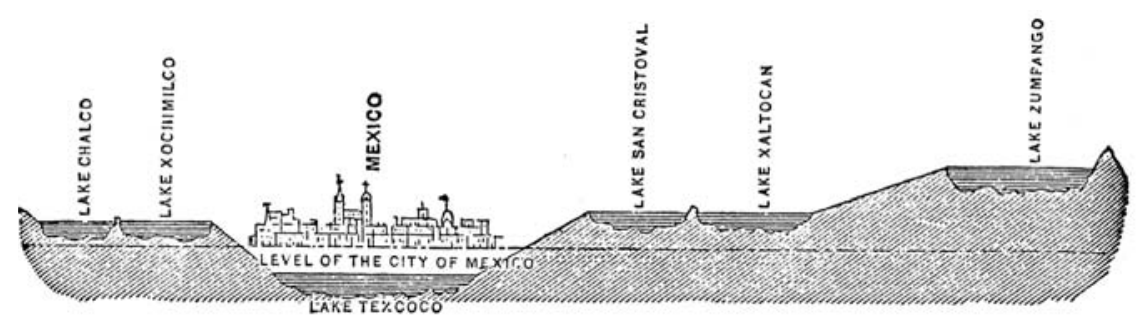

COMPARATIVE LEVELS OF LAKES.

2. Esquema comparativo del nivel de los lagos en la cuenca de México. Imagen tomada de William H. Bishop, Old Mexico and Her Lost Provinces: a Journey in Mexico, Southern California and Arizona by Way of Cuba, Nueva York, Harper and Brothers, I883, p. 46.

rebasaba su capacidad; en septiembre el lago de Texcoco comenzó el avance persistente sobre la capital, siendo la zona de oriente (la más cercana a Texcoco) la primera en quedar anegada; de esta crítica experiencia dieron cuenta los diarios de la ciudad. Enseguida referiré un par de testimonios particularmente interesantes por su tono irónico que revelan algo más que la vivencia de una inundación. El periódico La Orquesta publica una "Relación de las desgracias habidas en la isla de la Merced a últimas fechas"; la del 26 de octubre dice:

Una vendedora de cacahuates, aterrorizada por el ruido de las olas y por los bramidos del susodicho mar, se precipitó a él desmayada con todo y mercancía que, como deja entenderse, fue arrastrada violentamente por la corriente. La mujer se salvó, gracias a que no sabemos cómo pudo asirse con dientes y uñas a una chinela de un zuavo que a la sazón flotaba por allá a guisa de barquichuelo. ${ }^{3}$

Y la del 27 de octubre:

Al pasar a pie enjuto por uno de los puentes levadizos un piquete de soldados de esta fortaleza, ¡zaz! Desvanecido uno de ellos, zambullose en el agua, no habiendo podido salvar más que el pompón de su chacó, pues el infeliz soldado fue tragado enterito y con todo y fusil, por un corpulento ballenato. ${ }^{4}$

3. Jorge Tiburón, "Inundación. Relación de las desgracias habidas en la isla de la Merced a últimas fechas", La Orquesta, México, 28 de octubre de I865, p. 2.

4. Idem. 
Las dos breves crónicas son supuestas escenas ocurridas en la isla de la Merced, lo que subraya la identificación de la zona urbana más vulnerable respecto a la inundación, que fue el oriente; y también expone de manera indirecta pero muy efectiva la presencia de los zuavos, los soldados franceses que por entonces ocupaban la ciudad y que se asoman en la crónica al aludir a su uniforme o, mejor dicho, a ciertos componentes del peculiar atuendo militar, como las chinelas (una especie de calzado) y el chacó (una gorra rematada con una borla).

Además de las incisivas crónicas de La Orquesta, las caricaturas publicadas por esos días son significativas pues exponen una perspectiva y ayudan a inferir cómo se calificó un acontecimiento de tal género: la inundación como una catástrofe que debían remediar las autoridades y el lago como enemigo cosificado que se detendría ante las medidas tomadas por el Estado para salvaguardar la ciudad. Por otra parte, la postura del gobierno se halla en las memorias ministeriales que indican que el Imperio echó mano de los recursos que consideró más efectivos para el remedio, el instrumento del poder fue la ciencia, como lo enuncia desde el Ministerio de Fomento el funcionario e ingeniero Luis Robles Pezuela: "Efectivamente cuantos proyectos han sido presentados al Ministerio, tantos han sufrido el examen mío y el de la sección científica". En específico, fueron los ingenieros quienes ganaron la convocatoria para aplicar soluciones; ${ }^{6}$ la responsabilidad de los especialistas parece ser por todos conocida, ya que la prensa se ocupa de presentar a tales personajes y de exponer su vínculo con el poder. A inicios de septiembre se expresa tal postura en $L a$ Orquesta con una caricatura que patentiza de forma exagerada el fenómeno de la inundación en la ciudad: sobre una gran roca (que es a la vez una especie de bálsamo), un funcionario del gobierno funge como intermediario entre los habitantes de la capital (que se hunden indefensos en la masa de agua en que se ha convertido la cuenca) y un grupo de distinguidos personajes que se enfilan con objeto de presentar sus propuestas para el desagüe; ellos extienden sus planos ante nuestra mirada, sus proyectos son sus cartas de presentación o

5. "Desagüe del Valle de México", en Memoria presentada a S. M. el emperador por el ministro de Fomento Luis Robles Pezuela de los trabajos ejecutados en su ramo el año de 1865, México, Imprenta de J. M. Andrade y F. Escalante, I866, p. 8.

6. El ejemplo más claro del uso de la ciencia por el Estado está en las comisiones científicas que organizó el Ministerio de Fomento en diferentes momentos. Los equipos de ingenieros que formaron las comisiones (apoyados por artistas y fotógrafos) se volcaron sobre un área definida con el objetivo de obtener datos geográficos, geológicos, botánicos y en algunos casos sociales, para el reconocimiento del territorio nacional en fragmentos. 
DOI: http://dx.doi.org/10.22201/iie.18703062e.2011.98.2363

I I 2

CITLALI SALAZAR TORRES

las credenciales que los facultan como profesionales y les confieren autoridad y participación en el escenario de desastre que está al frente. El delegado, en tanto, pronuncia la frase que remarca que el gobierno es protector de los pobladores y proveedor de soluciones con el mejor recurso para el efecto. El caricaturista no pone en duda la situación de vulnerabilidad de los habitantes ni el papel de los profesionales o el de las autoridades; simplemente se burla de la eficiencia de los últimos para actuar ante la urgencia de la situación (fig. 3).7

El is de octubre, el ayuntamiento convocó a una sonada reunión con los ingenieros de la ciudad para intentar solucionar el problema que enfrentaban; llegaron a acuerdos parciales que se retomaron al día siguiente en otra reunión más nutrida, a la que asistió Maximiliano y en la que estuvieron presentes las principales autoridades de los distintos ramos de la ciudad y del Ministerio de Fomento. En las asambleas se discutían los numerosos proyectos que proponían terminar con el problema. ${ }^{8}$ Finalmente, se aprobó el proyecto de Francisco de Garay y a éste se le nombró director exclusivo, responsable e inspector de todos los trabajos en relación con las aguas en el llamado valle de México y de la inundación de la capital.9

Poco después de la sesión en que designaron el proyecto que se llevaría a cabo, el caricaturista Constantino Escalante hizo una divertida crítica, una vez más dirigida al reducido poder del gobierno ante las aguas que cubrían la ciudad. En la imagen, dos hombres están en primer plano con el agua cubriéndoles casi medio cuerpo, ellos señalan a la indefensa personificación de México que está tendida sobre aquel mar apenas respirando por una de las torres de la Catedral; un funcionario, que representa al "Exmo. Ayuntamiento" (según su banderín), se sitúa en uno de los puentes provisionales y bombea para sacar

7. Los ingenieros no fueron los únicos personajes en proponer soluciones, hubo ciudadanos que también lo hicieron; no obstante, las comisiones evaluadoras conformadas por los mismos profesionales exigieron seguir un protocolo que incluía la presentación de datos y mediciones, además de un presupuesto calculado.

8. Luis Espinosa, "Reseña histórica y técnica de las obras del desagüe del valle de México I856-I900. Libro Tercero", en Memoria histórica, técnica y administrativa de las obras del desagüe del valle de México I449-I90o, México, Tipografía de la Oficina Impresora de Estampillas Palacio Nacional, 1902, vol. I, p. 309.

9. Poco se sabe de la biografía de Francisco de Garay; lo que se ha rescatado del personaje está ligado a sus proyectos hidráulicos sobre la capital, y para ello remito a la citada Memoria histórica, técnica y administrativa de las obras del desagüe... y al ensayo de Adrián de Garay, Juicio sobre las obras del desagüe del valle de México: triunfo de las ideas del ingeniero don Francisco de Garay, México, Imprenta Mundial, I930. 


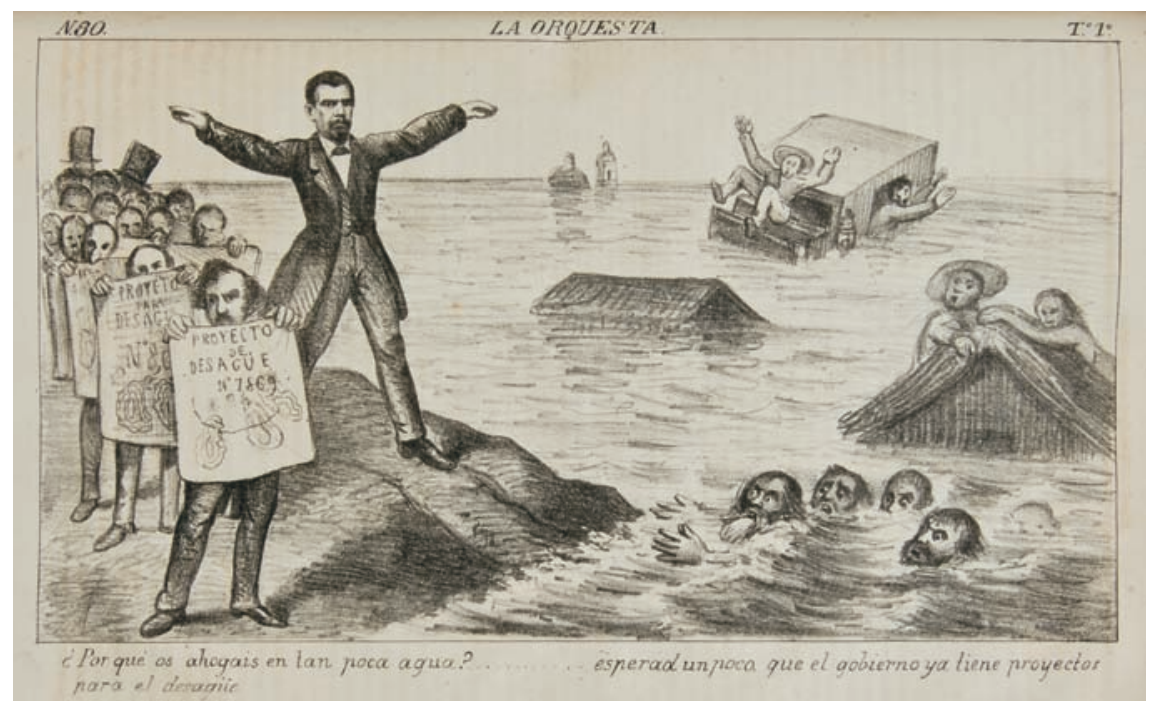

3. Anónimo, ¿Por qué os ahogais en tan poca agua? ... esperad un poco, que el gobierno ya tiene proyectos para el desagüe, publicada en La Orquesta, México, 6 de septiembre de I865, p. $2^{\mathrm{a}}$. Hemeroteca Nacional, UnAM.

el agua que tiene dentro la resignada capital. El diálogo de los personajes se refiere a las noticias sobre las obras del desagüe y a las medidas insuficientes y un tanto ridículas que tienen ante sus ojos para acabar con la situación que empeora (fig. 4).

La responsabilidad respecto al escenario de desastre recaía en dos instancias: el ayuntamiento de la capital y el Ministerio de Fomento, Colonización, Industria y Comercio. La primera corporación, local, tenía por tarea la resolución más inmediata de los problemas de sus habitantes; la segunda instancia, imperial, se debía encargar del proyecto más ambicioso, definitivo y de largo aliento de las obras de desagüe. Ambas agrupaciones actuarían acorde en una situación extraordinaria como la que ocurrió en los meses de septiembre, octubre y noviembre de I865.

El proyecto que había sido seleccionado ganador en octubre tardó un poco en llevarse a cabo y otro tanto en tener resultados comprobables. El plan para el desagüe urgente de la capital ante la inundación de ese año, ideado por el ingeniero Francisco de Garay, consistía básicamente en aislar el lago de Texcoco; dicho de otro modo, en impedir que los lagos del norte y los del sur siguie- 
DOI: http://dx.doi.org/10.22201/iie.18703062e.2011.98.2363

I I 4

CITLALI SALAZAR TORRES

ran vaciando sus excedentes en el más bajo. Logró esto con una serie de obras, de las cuales ahora nos interesa sólo una sección llevada a cabo en la parte sur de la cuenca de México: la que expresa el plano que es objeto de este ensayo.

Las corrientes del sur (que llegaban por los canales Nacional y Santa Martha) se detendrían ante un dique que se levantaría en la calzada de Culhuacán. Garay dice: "la gran dificultad que se presentaba, era levantar rápidamente un dique de dos metros de alto por cinco en la corona y nueve en la base, sobre la ruinosa calzada de 4000 metros de longitud; y esto, a medida que subía el agua con gran rapidez". ${ }^{\text {Io }}$

Las aguas del Canal Nacional fueron contenidas a la altura del pueblo de Culhuacán, cerrando el ojo de los puentes. De esta manera, se crearon vasos artificiales donde represaron las aguas que iban camino al lago de Texcoco, lo que por supuesto significó llevar la inundación a las fincas y los pueblos ribereños de los lagos de Chalco y Xochimilco. Las tierras anegadas que observamos en el plano corresponden a los que eran terrenos de la hacienda de Coapa y de San Antonio, principalmente.

\section{El plano de Garay}

El plano general del terreno que comprende las obras del desagüe ejecutadas en el sur del valle de México... está fechado en diciembre de I 866 y tiene como objetivo ser un testimonio o un reporte del dique de Culhuacán y de la permanencia de la inundación en el área que expresa.

Se trata de un plano en formato horizontal dividido en tres partes; la superior contiene la información básica (nombre del plano, fecha, autoría y adscripción) y las escalas en una pequeña sección al extremo derecho.

Un segundo apartado está a la izquierda, a manera de columna, donde se presentan algunas secciones transversales del dique de Culhuacán divididas por fechas que van de enero a diciembre de I 866 y que informan sobre el monitoreo del nivel de las aguas en distintos tramos del dique durante ese año. Los cortes se organizan por números romanos en sentido descendente; la misma numeración la ubicamos en el plano en referencia al corte transversal que presenta el autor.

Finalmente, la tercera sección del trabajo es la representación del territorio que se figura como contenido en una ventana y tiene límites muy preci-

Iо. Memoria histórica..., op. cit., p. 3 II. 


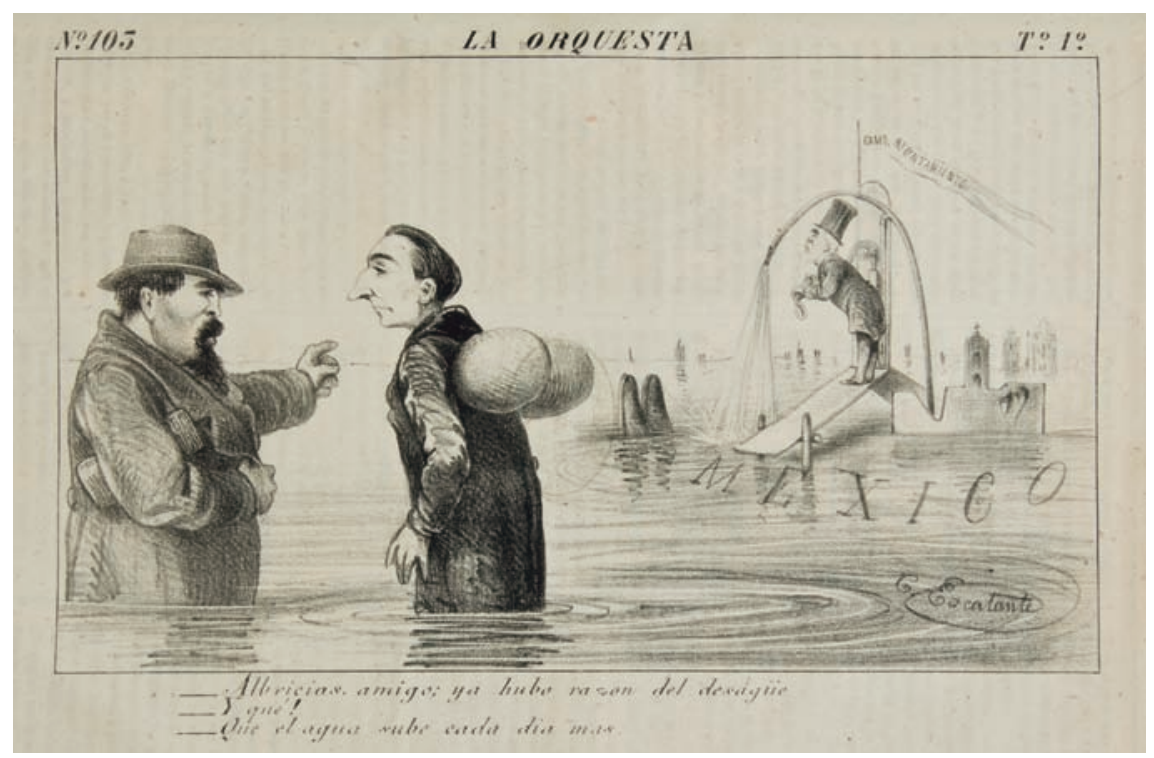

4. Constantino Escalante, “Albricias, amigo; ya hubo razón del desagüe. Y qué! Que el agua sube cada día más”, publicada en La Orquesta, México, 25 de noviembre de 1865 , p. $2^{\text {a }}$. Hemeroteca Nacional, UnAM.

sos y reveladores. Al norte está la ciénega de Aculco, que enmarca al pueblo de Mexicalcingo, sitio referente a un memorable dique de otros tiempos y que fue un segundo punto considerado para represar las aguas del sur que iban camino a Texcoco. Al sur está el dique de Más Arriba, otra obra realizada en el mismo año de la inundación y que fue el principal obstáculo para contener las aguas del lago de Xochimilco; este dique sería objeto de otros proyectos por ser clave en la entrada de canales navegables. Hacia el poniente, el límite es el pueblo de Churubusco, con la indicación de su convento que circunscribe las obras proyectadas alrededor de Taxqueña y del mismo río Churubusco. La sección más atractiva de este plano es, sin duda, la del límite oriente, donde figura completo el cerro de la Estrella, que sería el referente, en uno de los extremos, del dique de Culhuacán.

Finalmente diremos que en el extremo superior derecho se colocan las orientaciones astronómica y magnética (con el norte hacia arriba), lo cual permite situar el pedazo de terreno representado respecto a los puntos cardinales 
y en especial con relación al norte terrestre. También es importante notar que la carta se firma en el extremo inferior del mismo lado.

El dique de Culhuacán es la obra hidráulica recién construida, que protagoniza el plano como información y constancia. Aparece al centro de la composición, destacado con rojo y glosado con letras grandes.

\section{Descripción del territorio en el plano}

El dique de Culhuacán consignado en el trabajo del ingeniero Garay va del cerro de la Estrella (a la altura del pueblo de Culhuacán) al puente de Taxqueña. Hacia la mitad hay una doble línea roja referente a una caja proyectada para transportar un posible excedente de agua del río Churubusco al vaso artificial (fig. 5b).

La caja de agua posiblemente es obra algo posterior al dique de Culhuacán, proyectada por temor a una temporada de copiosas lluvias en lo sucesivo y pensada una vez que se cumplió el primer objetivo de formar vasos artificiales al sur del dique. También se observan delgadas líneas rojas y azules diseminadas en varios puntos del territorio, que corresponden a otras vertientes hidráulicas no naturales y de menor importancia. Las líneas en rojo se diferencian porque pueden ser las extensiones proyectadas o últimas adhesiones a las ya existentes, por ejemplo, el acalote de la hacienda de los Portales; en esta área, que se detalla en la figura 5 a, se colocan referencias constructivas como una troje o la capilla de las Ánimas y La Hermita (sic), contiguas al camino a México (que corresponde a la actual calzada de Tlalpan). Obsérvese también la descripción del terreno, como el banco de arena formado por el río Churubusco que está flanqueado por tierras de cultivo.

Proyectar obras de ingeniería hidráulica para la cuenca de México significaba, por un lado, intentar contener los lagos que rodeaban al llamado valle y, por el otro, dirigir los diferentes brazos acuáticos. La capital y los poblados que la rodeaban contenían zonas chinamperas y las numerosas vertientes de agua se usaban como vías para el comercio o el simple traslado, por lo cual el cierre de los canales hacia el lago de Texcoco significó interferir con la economía a escala individual y comunitaria; ni qué decir de las tierras anegadas que se volvieron zonas pantanosas infértiles por varios ańos. Así pues, en el tiempo subsiguiente a la inundación, lo más urgente era recobrar la cotidianidad acuática de la cuenca y los ingenieros estaban obligados a replantear proyectos para evitar un caos de otro género, el económico-social. 
DOI: http://dx.doi.org/10.22201/iie.18703062e.2011.98.2363

LA INUNDACIÓN EN EL SUR DE LA CUENCA DE MÉXICO II7

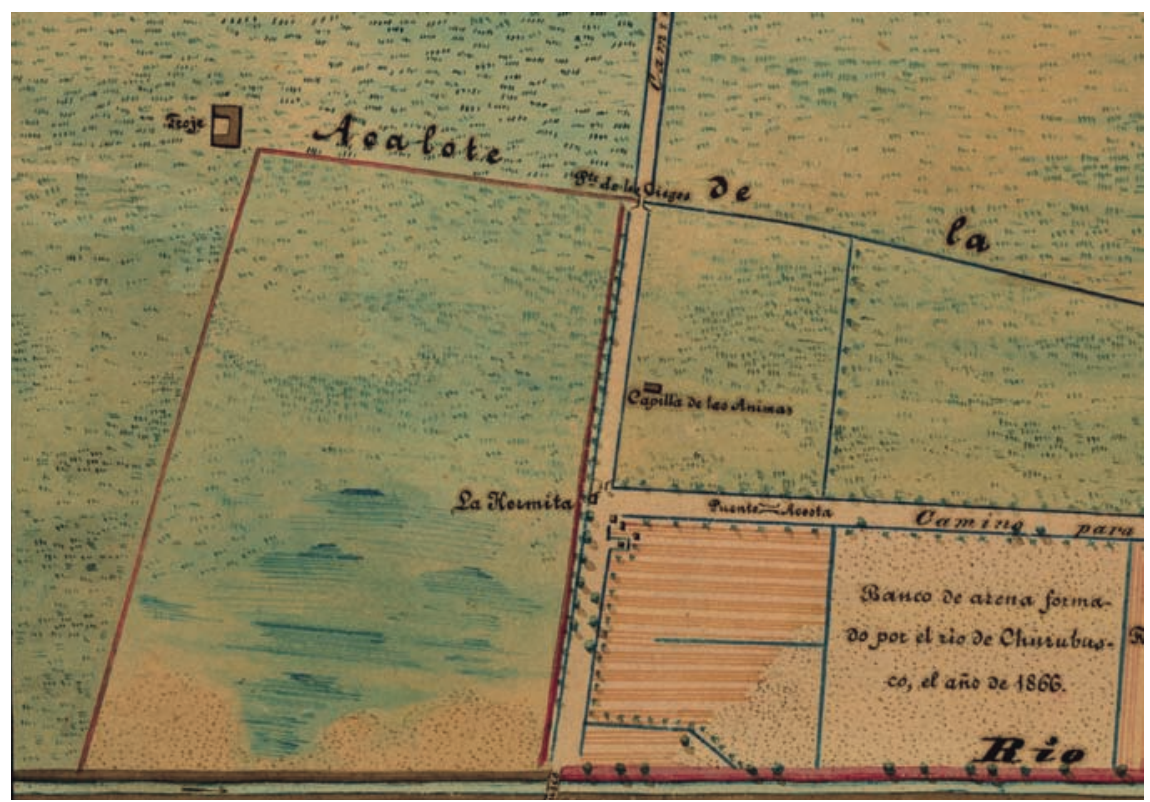

5a y b) Detalles del Plano general del terreno que comprende las obras del desagüe ejecutadas en el sur del valle de México..., op. cit.

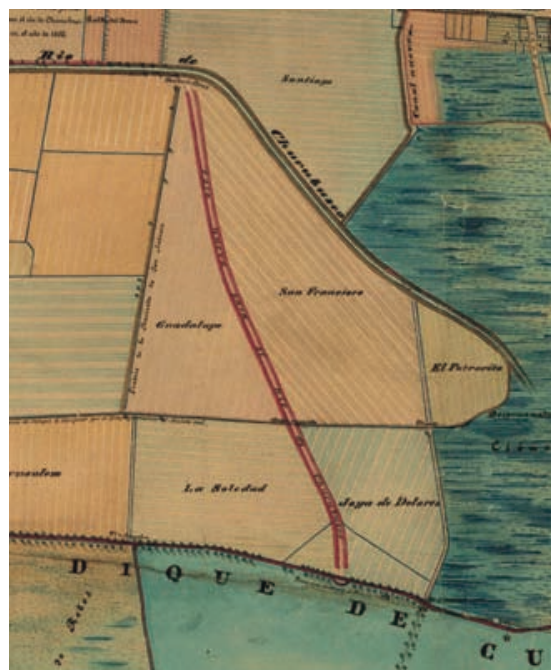


Como he sugerido en líneas anteriores, el plano de Garay tiene una cualidad destacada: la atención y el cuidado de hacer una representación detallada de un territorio, lo cual tiene como resultado una excelente descripción de las diferentes zonas que expresa. Es decir, deja a la vista los terrenos de cultivo, las áreas chinamperas y la ubicación y el tamaño de asentamientos (pueblos, rancherías, haciendas y barrios); sitúa referencias arquitectónicas como las iglesias u otro género de grandes construcciones (cascos de haciendas y trojes), y apunta la concentración de árboles, caminos, canales y acalotes y, sobre todo, las superficies que represaron el agua y la cantidad de este elemento contenido en cada área. Por el empeño de tal tipificación acuática y el gran valor de esa información, el color resulta especialmente apreciable en este plano; es decir, el color es información. Incluso la excepcional presencia del líquido sobre los terrenos del sur en ese momento pudo haber sido la causa de que se eligiera colorear este plano, lo cual, para nuestra fortuna, lo vuelve muy atractivo visualmente.

Así, observamos un catálogo de gamas de azul; en algunas zonas hay tonos de verde azulado para expresar poca presencia de humedad sobre un área de vegetación, lo cual se refuerza con diminutas líneas verticales que sugieren pastizales bajo el agua. En otras, la composición del suelo es más bien arenosa, por lo cual se entremezcla el celeste con tonos marrones (fig. 6a).

Los pantanos se diferencian por azulados más intensos donde mezcla los trazos de pastizales junto a líneas horizontales entrecortadas que indican mayor cantidad de agua (fig. 6b). Las tierras completamente anegadas se tiñen llanamente (fig. 6c).

La característica interpretativa ${ }^{\text {II }}$ de este plano mediante el hábil uso de las convenciones cartográficas (donde se incluye el color) podría tener su origen en la importancia que dio Francisco de Garay a ubicar el contexto de las obras hidráulicas y, sobre todo, a buscar una integración en la mirada de la ingeniería de los componentes sociales del área que fue directamente afectada por la anegación. Volveremos a este argumento fundamental más adelante cuando, comparativamente, apreciemos la forma en que Garay decidió hacer el registro del territorio.

Hay otras características formales de este plano que llaman la atención y son las que a continuación examinaré.

II. No podemos ignorar el hecho de que la imagen de Garay, si bien tiene un gran valor descriptivo, es una interpretación del territorio que se puede cotejar con otras versiones. 

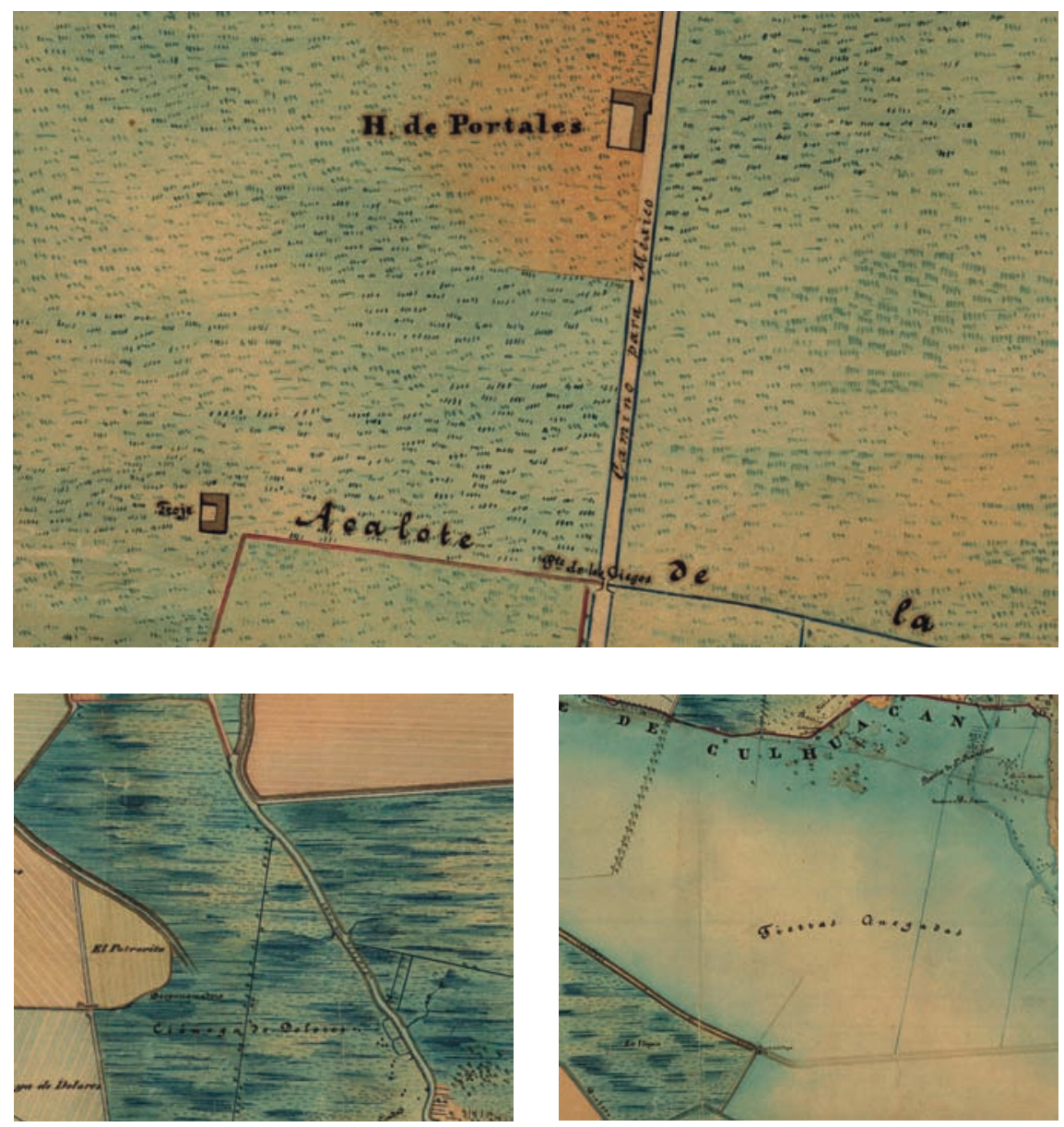

6a-c) Detalles del Plano general del terreno que comprende las obras del desagüe ejecutadas en el sur del valle de México..., op. cit.

\section{Cartografía decimonónica, imágenes de prestigio}

En I866, año en que Garay elaboró este plano, no existía un lineamiento oficial para presentar cartas de proyección o de constancia de obras ya ejecutadas. Y sólo en I877 el ministro de Fomento, general Vicente Riva Palacio, nombró como encargado de la sección de Geografía, Estadística y Cartogra- 
DOI: http://dx.doi.org/10.22201/iie.18703062e.2011.98.2363

fía al ingeniero Vicente E. Manero. En el equipo que reunió estos amplios rubros, el ingeniero encargado de la subsección de cartografía fue Agustín Díaz, quien tiempo después presentó el "Informe sobre el estado actual de la cartografía", que es una desalentadora valoración retrospectiva de los productos de esta disciplina. Es bien sabido que una de las principales cualidades de una imagen cartográfica es que contenga información verificable en el terreno; es decir, que lo anotado en cada trazo corresponda en grado medible con aquello que representa. Así, el levantamiento correcto de la información en el terreno, que después sería vaciado en una carta, era el primer paso de un plano bien realizado. Lo que seguía en el proceso consistía en expresar estos datos a partir de convenciones reconocidas por la comunidad a la que estaba dirigida, es decir, a los ingenieros, quienes elaboraban y leían los planos y debían poseer un lenguaje estandarizado tanto gráfico como de símbolos. El Ministerio de Fomento, como encargado de la estadística, la colonización y las obras constructivas sobre el territorio de todo el país, tenía un nutrido acervo de cartografía que debía contener información cuantiosa sobre los rubros correspondientes y que se podrían inventariar, en primera instancia, en forma de convenciones figurativas; no obstante, el diagnóstico de Agustín Díaz apunta otras condiciones:

La anarquía que se advierte en toda esta colección sobre las especies adoptadas de proyecciones, escalas, signos, tipos, caracteres, etc., hacen en extremo dificultosa su comparación; y las diferencias en los nombres de los lugares, en sus categorías y en sus situaciones, tanto absolutas como relativas, casi imposible su concordancia [...]

Tal confusión no debe de admirar, pues cualquier persona medianamente ilustrada comprende que sin la reglamentación previa de todos los pormenores, y sin plan preconcebido que los ligara, por buenos que fuesen todos los trabajos ( $\mathrm{y}$ ciertamente que los hay) en su conjunto tenía que producir aquel resultado. ${ }^{\text {I2 }}$

El problema era más grave en tanto que no existía la garantía de un proceso profesional en el levantamiento de datos sobre el terreno a partir de lo más básico, como por ejemplo la determinación de las coordenadas de latitud y

I2. Memoria presentada al Congreso de la Unión por el secretario de Estado y del Despacho de Fomento, Colonización, Industria y Comercio de la República Mexicana Vicente Riva Palacio correspondiente al año transcurrido de diciembre de I876 a noviembre de I877, México, Imprenta de Francisco Díaz de León, I877, p. 476. 
longitud que sitúan geográficamente una porción de territorio, es decir, situar en ejes una fracción de terreno que sería trasladado a una carta:

En cuanto a los catálogos de posiciones geográficas, con excepción de las obtenidas de las Comisiones de límites, Valle de México, y una que otra aislada de observaciones más recientes, por lo general se han coleccionado sin ninguna discusión sobre su procedencia, pues careciendo de los datos que las produjeran, fuerza era aceptarlas bajo la única garantía del nombre de sus autores; lo que explica bastante el poco valor de muchas de ellas. ${ }^{13}$

Entonces, desde la perspectiva de Agustín Díaz, enfrentamos varios panoramas dentro de la producción cartográfica de las décadas anteriores a I877. En una colección de planos de un ministerio, que debían ser de utilidad para el conocimiento y reconocimiento del territorio y para fines más prácticos en tareas administrativas (entiéndase: para obtener estadísticas de todo tipo), no había concordancia de forma. Además, existían serias dudas respecto a la veracidad de los datos más básicos que se levantaban sobre el terreno, lo cual ocasionó que algunas cartas se hicieran sin esos datos o con información errónea.

Finalmente, hay un tercer punto importante que no menciona abiertamente Díaz, pero que está implícito en el diagnóstico de la cartografía: el lugar de los ingenieros que ejercen su papel de profesionales y de funcionarios, pues son actores políticos que toman partido y se adhieren a una ideología e incluso la expresan al ejercer su profesión. Así se explica la presencia o ausencia de destacados ingenieros que en algún momento tuvieron protagonismo en ciertas gestiones y que desaparecieron de otras; de la misma manera se entenderá que los funcionarios tuvieron ingenieros de cabecera a los que encargaron obras o que ganaron los concursos convocados por las mismas autoridades. Un ejemplo lo tenemos en el famoso ingeniero geógrafo Francisco Díaz Covarrubias, quien abiertamente se adhirió a la figura de Benito Juárez; el importante ingeniero tuvo una intensa actividad docente formando varias generaciones de profesionales y consagrando tal tarea en valiosas obras didácticas; por otro lado, estuvo al frente de empresas de gobierno, como la formación de la carta topográfica del llamado valle de México en I856 y el establecimiento del Observatorio Astronómico en Chapultepec, proyecto que se truncó con la lle-

13. Idem. 
gada de los franceses y que sería retomado en I877 con otro ingeniero a cargo. Otro ejemplo lo hallamos en el ingeniero civil Francisco M. Jiménez, en quien se apoyó el ministro Vicente Riva Palacio para que durante su gestión desarrollara una propuesta de estatuaria pública; el mismo ministro eligió a otro ingeniero (esta vez militar): se trata de Agustín Díaz, quien encabezó la ambiciosa comisión de levantar, bajo una misma norma, las cartas geográficas de toda la República mexicana.

De lo antes dicho se puntualizan algunas premisas a considerar en el estudio de la cartografía del siglo xix en México:

$I^{\text {a }}$. Los planos no siempre tienen un valor de exactitud, es decir, no necesariamente contienen información que se corresponda en grado medible con aquello que expresan.

$2^{\mathrm{a}}$. Los planos, aun cuando tengan cualidades formales, no siempre fueron eficientes debido a que existía un desconcierto en las convenciones dentro de las ingenierías que tenían la producción cartográfica en sus manos.

$3^{\mathrm{a}}$. Muchos ingenieros fueron actores políticos y su presencia o ausencia en el campo profesional respondía a una serie de contactos en los ramos administrativos.

Ahora bien, para valorar un plano de I 866 ubicado en los años de anarquía que refiere Agustín Díaz en el citado informe, será preciso ceñirnos a su especificidad dentro de la ingeniería.

El Plano general del terreno que comprende las obras del desagüe ejecutadas en el sur del valle de México... realizado por Francisco de Garay se clasifica, según los criterios de la época, como un plano de desagüe correspondiente al grupo de cartas hidrográficas $y$, para situarlo en una producción similar, me referiré a continuación a un par de ellas.

\section{Cartas hidrográficas}

El 25 de abril de i866, Constantino Escalante manifiesta algunos temores de los capitalinos y de los periodistas para aquel año, en la caricatura "Los tres enemigos capitales de la capital/Los tres enemigos periódicos de los periodistas", de la cual es interesante particularmente una viñeta que corresponde a la amenaza de una nueva inundación en la ciudad; en ella, vestido con levi- 


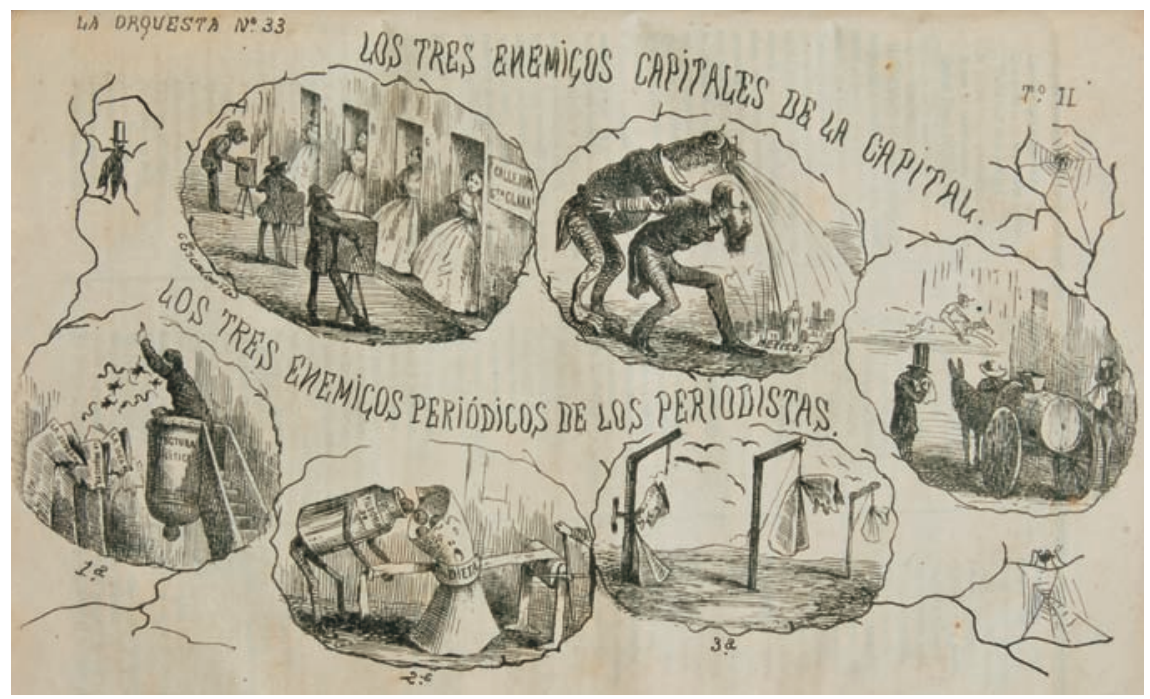

7a y b) Constantino Escalante, "Los tres enemigos capitales de la capital/

Los tres enemigos periódicos de los periodistas", en La Orquesta, México, 25 de abril de I866, p. 3. Hemeroteca Nacional, UNAM.

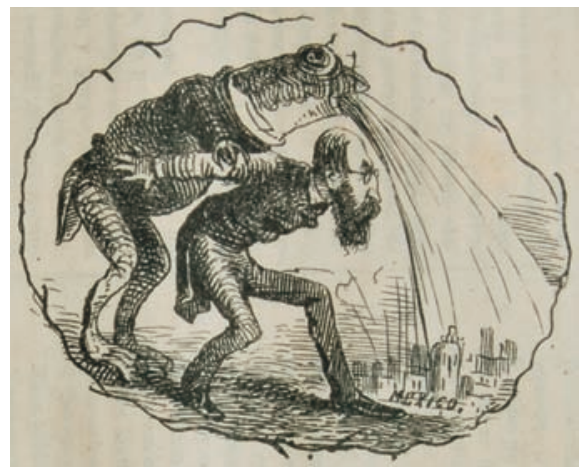

ta, un monstruoso anfibio vomita con toda su fuerza sobre la empequeñecida capital, al tiempo que un descomunal funcionario-ingeniero intenta detener la embestida con poco éxito (figs. $7 \mathrm{a}$ y $7 \mathrm{~b}$ ).

En los últimos meses de I865, se minimizó el riesgo de la desastrosa inundación en la capital, no obstante que el lago de Texcoco estaba lleno y que se habían formado vasos artificiales al sur, por lo que un periodo de copiosos aguaceros en los meses de mayo a agosto de 1866 provocaría un irremediable y nuevo desbordamiento sobre la ciudad. Ante el posible escenario, las autoridades y 


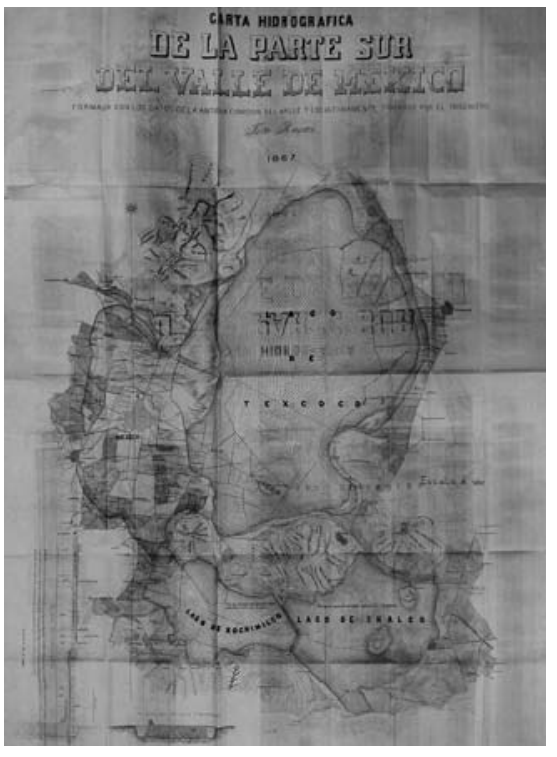

8. Carta hidrográfica de la parte sur del valle de México formada con los datos de la antigua Comisión del Valle y los últimamente tomados por el ingeniero Tito Rosas, I867, publicada en la Memoria... op. cit. (vid. n. I4).

los ingenieros se pusieron a trabajar para, por un lado, consagrar las obras del año anterior y recuperar en lo posible la cotidianidad de la vida en los habitantes y, por el otro, llevar a cabo nuevas e inmediatas labores para el desagüe. Una de las soluciones fue la construcción de un dique de circunvalación, de lo cual hay constancia, pero ahora me interesa más hablar de la preocupación de las autoridades y los ingenieros en los años subsiguientes a la inundación de I865, expresada de manera clara en la Memoria de Fomento de I868.

En esta publicación está anexado un interesante plano de desagüe hecho como parte de la valoración que el ministro de aquel año, Blas Balcárcel, solicitó a los ingenieros con el objetivo de recobrar la cotidianidad acuática de la ciudad y las zonas aledañas; y es que lo que motivó al funcionario a pedir tal estudio fueron las constantes y fundadas quejas de los transportistas y de los pasajeros, así como el perjuicio de la misma capital que se veía abastecida tardíamente de los productos provenientes de las áreas sureñas de la cuenca. Uno de los diagnósticos que se llevaron a cabo dejó constancia en la Carta hidrográfica de la parte sur del valle de México formada con los datos de la antigua Comisión del Valle y los últimamente tomados por el ingeniero Tito Rosas ${ }^{\mathrm{I} 4} \mathrm{de}$ I867 (fig. 8).

I4. Véase Memoria que el secretario de Estado y del Despacho de Fomento, Colonización, 


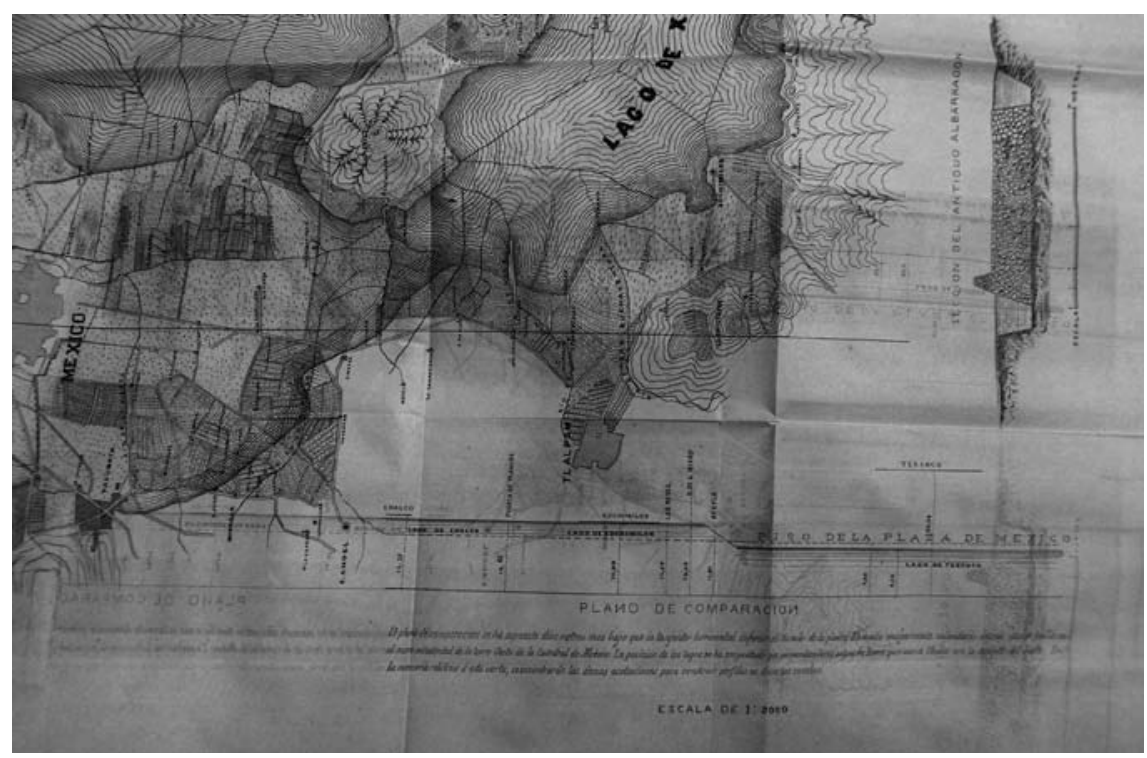

9. Detalle de la Carta hidrográfica de la parte sur del valle de México, plano de comparación de los lagos del sur con relación al de Texcoco y la ciudad de México.

El estupendo plano tiene formato vertical y todos sus elementos aparecen organizados dentro de un mismo margen: está orientado únicamente por el norte astronómico, tiene escala y la firma del ingeniero forma parte del título que figura escrito en la parte superior. El trazo no satura la carta (a comparación del plano de Garay); el motivo principal son los lagos del sur, su situación y el camino de sus vertientes rumbo al de Texcoco. Es notable la valiosa información sobre la ubicación general de las aguas del sur y su recorrido, donde se registran otros componentes naturales (como la topografía) y humanos (las ciudades, los pueblos, las zonas de cultivo, etcétera). Además de esta vasta descripción del terreno, en el costado inferior izquierdo, en un corte transversal, ofrece un plano de comparación de los lagos del sur (Chalco y Xochimilco) respecto al nivel del de Texcoco y del piso de la ciudad de México (fig. 9). Junto a esta sección hay otro corte transversal de un antiguo albarradón (¿acaso el de San Lázaro?) del que no se detalla la ubicación. No es ocioso dete-

Industria y Comercio presenta al Congreso de la Unión, México, Imprenta del Gobierno en Palacio a cargo de José M. Sandoval, ı868, documento anexo al final del tomo. 
nernos a observar la sección que un año antes representó Garay en su Plano general del terreno... Se ve la cercanía del lago de Xochimilco con el de Texcoco, en medio de los cuales se halla el cerro de la Estrella, y encontramos también la vertiente que rodeaba esa eminencia en su camino hacia el vaso de la cuenca. Si se observa más de cerca, se verá el dique de Culhuacán, que el ingeniero Rosas también detalla en su trabajo (fig. Io).

La Carta hidrográfica de la parte sur... está respaldada por datos de una notable comisión de ingenieros que se dieron a la tarea de medir el territorio de la cuenca mexicana, financiada por el Ministerio de Fomento unos años antes; llama la atención que el ingeniero Rosas creyera indispensable apoyar su plano precisamente en esos datos y manifestarlo así en un largo título, lo cual obliga a recapacitar sobre la importancia de los proyectos de ingeniería hidráulica para la ciudad y la necesidad de avalarlos con datos y mediciones ya aceptadas por el prestigio de comisiones precedentes; así, Rosas justifica su propuesta en cierta labor (¿tradición?) profesional, que es la escuela de Francisco Díaz Covarrubias. Recordemos que el trabajo fue solicitado por el mismo ministerio y que forma parte de la memoria de la institución; es decir, la carta de Rosas iba dirigida al ministro Balcárcel y a los jefes correspondientes de las secciones de aquella instancia.

Por otro lado, entre las diferencias con el plano de Garay, hay que decir que el de Tito Rosas es mucho más ambicioso y, al intentar expresar una extensión del territorio más vasta, está condenado a perder detalles y a no hacer efectiva la descripción y ubicación de las áreas anegadas y las ciénegas temporales, o a anular las zonas de pedregales y las arboledas; también es importante notar, a partir de la comparación, la gran riqueza descriptiva que brinda el recurso del color en la cartografía, que resulta más dramática tratándose de planos hidrográficos.

Como ya mencionamos, la carta de Rosas formó parte de una valoración sobre el territorio en 1867; sin embargo, falta aclarar cuál fue el dictamen de esa comisión.

Se ha dicho que la construcción de varios diques al sur de la cuenca transtornó el transporte en las vertientes acuáticas; si bien hubo arreglos urgentes, no se volvió a una situación regular, ya que las canoas que transportaban mercancías o personas tenían que hacer varios transbordos en su recorrido del sur al centro. Los años de I866 y I867 no fueron de copiosas lluvias, gracias a lo cual no se verificaron anegaciones similares a la de i865; no obstante, dos años después, las consecuencias de aquel año funesto todavía se vivían. El dictamen 


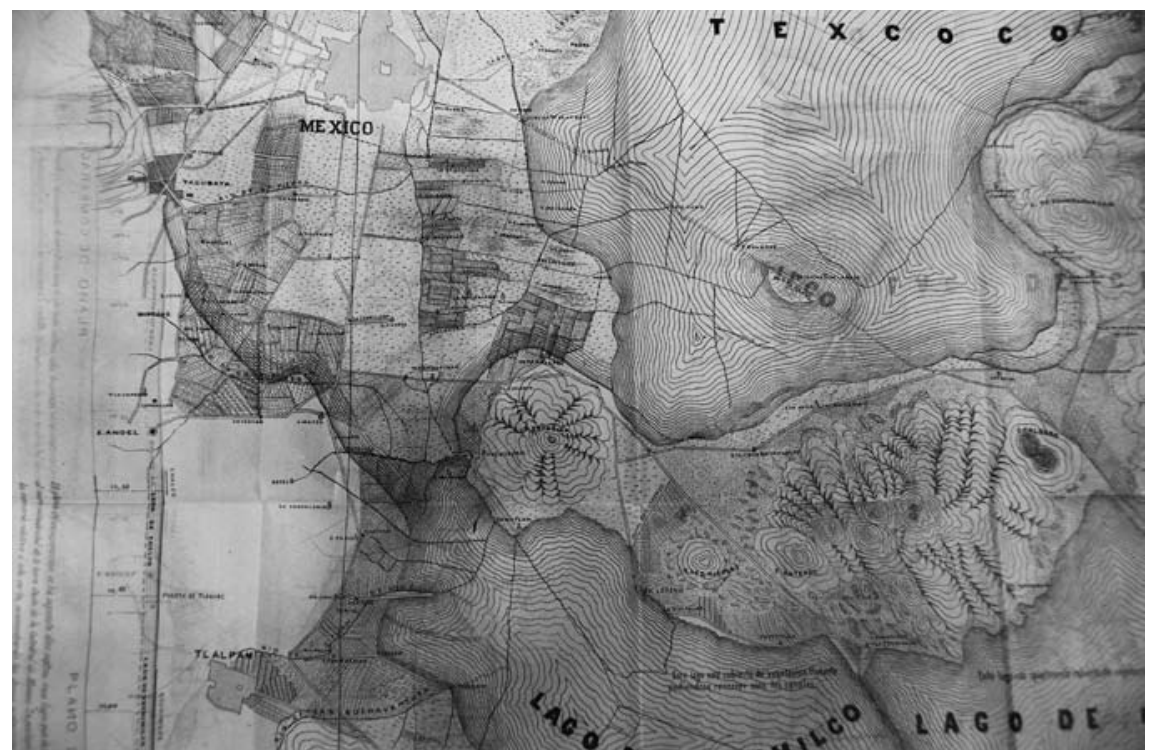

Io. Detalle de la Carta hidrográfica de la parte sur del valle de México, sección del cerro de la Estrella donde se halló el dique de Culhuacán.

de las visitas de los ingenieros al sur de la cuenca fue terminante: no era posible aún derribar los diques; la cantidad de agua que todavía represaban no podía dar al lago de Texcoco, ya que el nivel subiría peligrosamente, considerando también que se avecinaba la época de lluvias. Así, las tierras anegadas debían liberarse poco a poco vaciando su contenido en los canales navegables y siempre debía controlarse el volumen fluvial a partir de las compuertas y las esclusas distribuidas en diferentes secciones.

Un plano de desagüe que resguarda la Mapoteca Orozco y Berra, hecho por el mismo ingeniero Tito Rosas y dibujado por Luis G. de la Barca, lleva el título de Proyecto de una esclusa para establecerla en Más-Arriba (fig. II). Es un proyecto que consta de dos partes: en la primera se asienta la información básica referente al título del plano, el crédito del realizador y del dibujante, la relación de escala y un corte transversal de la esclusa que parecería más cercano a una ilustración por su tamaño y por la forma en que se integra al diseño. La segunda parte es otra hoja que está firmada únicamente por el ingeniero Rosas, consigna el proyecto de la esclusa en el contexto y lleva un título secundario: Croquis del canal de la Viga a Más Arriba (fig. I2). El croquis, de difí- 


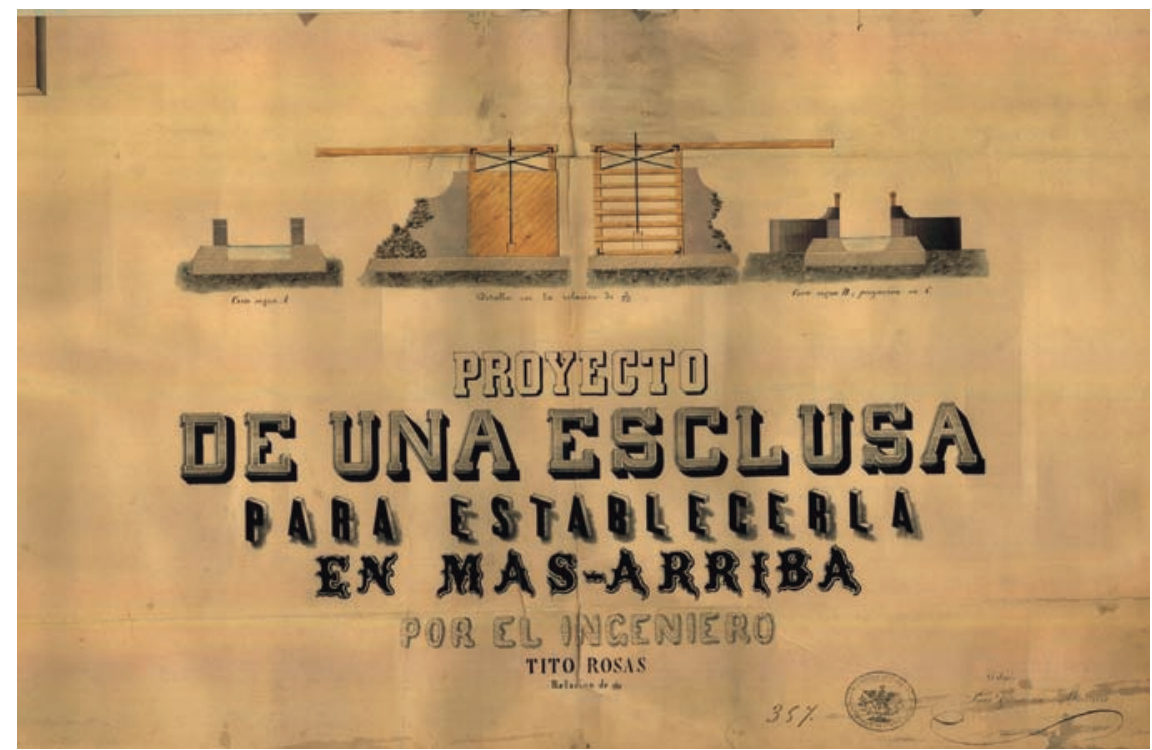

I I. Tito Rosas y Luis G. de la Barca (dibujó), Proyecto de una esclusa para establecerla en Más-Arriba, mayo de I869, México, Mapoteca Manuel Orozco y Berra, Servicio de Información Agroalimentaria y Pesquera, SAGarpa núm. 405-A-20.

cil lectura, tiene un orden caprichoso; es de formato horizontal y el título del plano está inscrito en el extremo superior izquierdo; bajo este nombre, cuidadosamente caligrafiado, se dibuja un extenso canal con una línea sinuosa entrecortada constantemente por números y por canales secundarios que salen del principal; se trata del canal navegable más importante que iba de Xochimilco a San Lázaro y del que no se consigna el nombre por variar en distintos puntos; tiene como extremos el dique de Más Arriba (que vemos en su límite derecho) y en la contraparte la garita de San Lázaro; una discreta flecha establece la orientación norte (sólo el norte magnético) que apunta a la izquierda del plano. El canal tiene varios detalles interesantes que vale la pena notar: ante todo, es importante ubicar la vertiente acuática también en el plano de Garay, siendo el que recorre las faldas del cerro de la Estrella y que se dibuja incluso bajo las tierras anegadas, atraviesa Mexicalcingo y sigue su camino hacia el lago de Texcoco. En el proyecto de Tito Rosas (siguiéndolo de derecha a izquierda), comienza en el dique de Más Arriba, registra el de Culhuacán (obra del ingeniero Garay) y después pasa por Mexicalcingo (a partir de su puente del mismo 


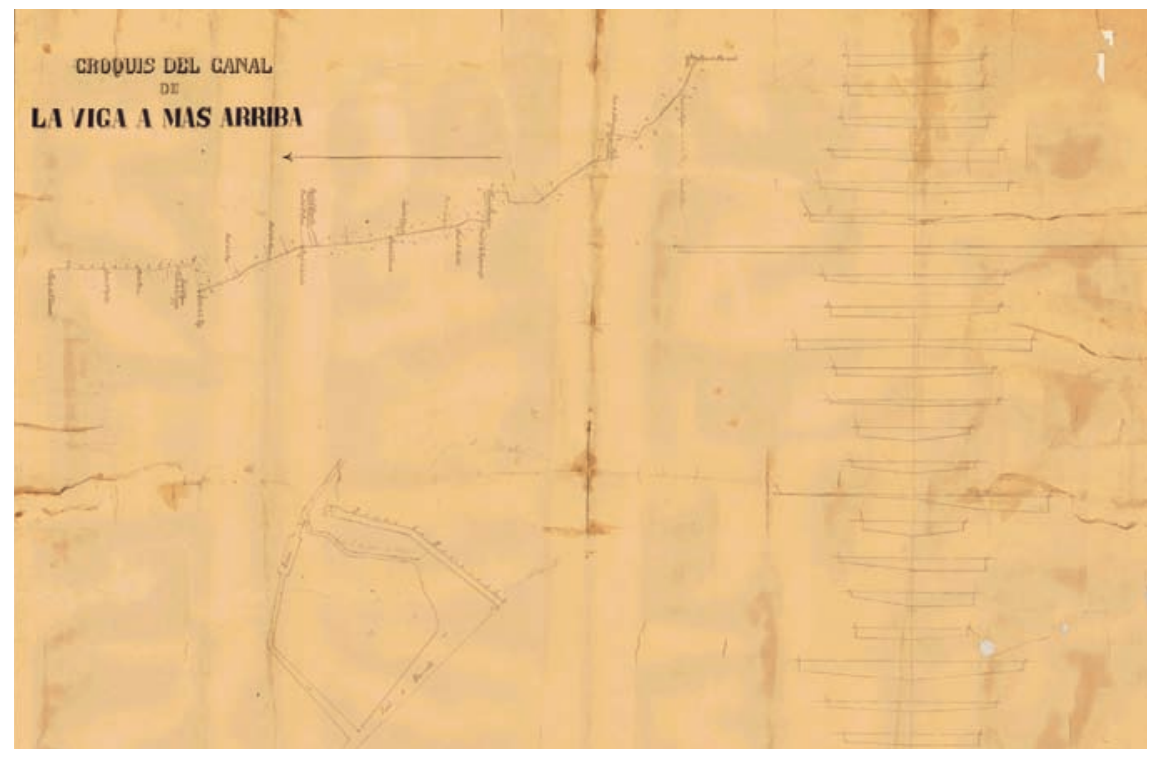

I2. Tito Rosas, Croquis del canal de la Viga a Más Arriba, mayo de I869. Mapoteca Manuel Orozco y Berra, Servicio de Información Agroalimentaria y Pesquera, SAGARPa núm. 405-B-25.

nombre), hasta llegar al de Iztacalco y después a la garita de la Viga, continúa a la de Coyuya y finalmente a San Lázaro. Abajo del largo trazo del canal (y sin relación aparente con él), Rosas dibuja (con otra orientación) el detalle de la sección específica donde se instalaría la esclusa proyectada (en Más Arriba) (fig. I3).

Una esclusa para un canal cercano a un dique sería muy útil, pues al nivelar el caudal que haría navegable la vertiente dejaría pasar sólo el agua necesaria para que las canoas pudieran recorrerlo; así, vemos un pequeño canal de alimentación cercano a la esclusa. Finalmente, hay una tercera sección en el plano de Rosas que ocupa la mitad derecha de la carta y refiere cortes transversales del canal en varios de sus puntos, lo que da conocimiento del nivel de caudal necesario en cada tramo para hacerlo navegable. Los cortes tienen números que se corresponden con los anotados en el croquis del canal, lo cual hace ubicable cada sección transversal en el terreno; al final de esta lista está la información de las escalas. Como última valoración, hay que precisar que la firma del ingeniero Tito Rosas está en el extremo inferior izquierdo, junto a la fecha: mayo de 1869 . 


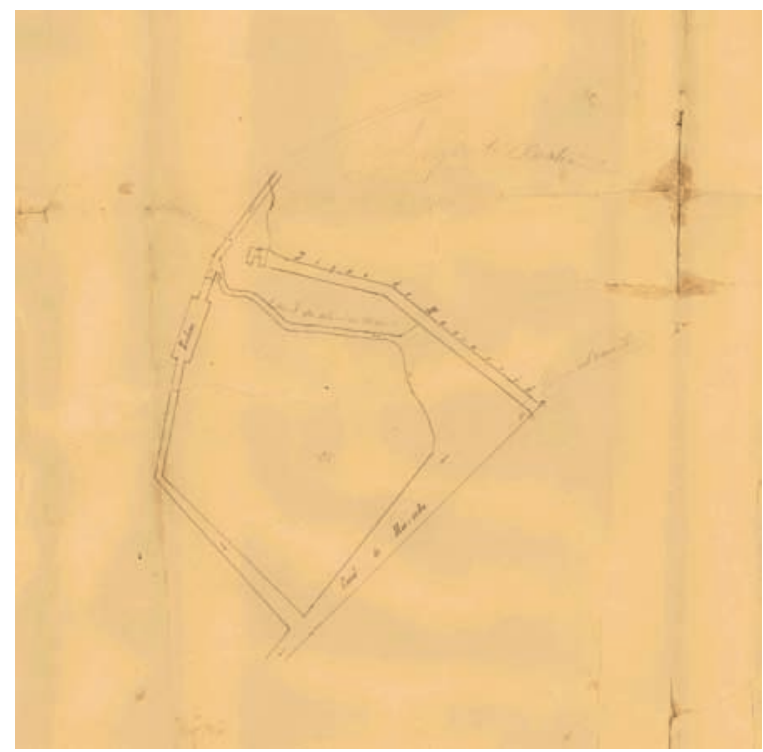

13. Detalle del Croquis del canal de la Viga a Más Arriba, donde se especifica la ubicación de la esclusa proyectada.

Es indudable la utilidad que tendría para los ingenieros un conocimiento de este tipo, si bien hay que notar la complicada lectura del plano de Tito Rosas y la dificultad actual de establecer la veracidad o cientificidad de las medidas de las secciones transversales y de las situaciones exactas y ubicaciones relativas respecto a otros puntos que consigna su plano. Ahora quiero destacar la comparación del trabajo de Rosas con el de Garay, ya que son temáticas similares y cercanas en tiempo. La primera salvedad es que el primero nombra su proyección como croquis y el segundo como plano. No obstante, esta diferencia en la designación no parecería ser un gran obstáculo para la organización de los elementos de la carta, en lo que de entrada se nota un gran contraste, más aún cuando en ambas cartas hay cortes transversales que se corresponden con una referencia territorial también consignada. El croquis de Rosas tiene título, firma, orientación y escala (datos básicos), pero la gran ausencia es la descripción del canal que es el motivo de su proyecto; es decir, ¿¿ónde está ubicado con relación a la cuenca?, ¿qué referencias topográficas y humanas lo circundan?, ¿por qué es importante la esclusa como proyecto de ingeniería hidráulica? Todas estas precisiones las conocemos gracias al plano de Garay y 
al contexto histórico que se ha descrito en este ensayo. Es cierto que un proyecto de ingeniería hidráulica expresado en cartografía no requiere tener más que los elementos que se hacen necesarios dentro de su disciplina y respecto a su especialidad, por lo cual no es posible pedir más elementos de los que aporta el croquis de Rosas; no obstante, también nos brinda la oportunidad de valorar de distinta manera el plano de Garay, que, como sostuve en líneas anteriores, tiene la virtud de ubicar las obras hidráulicas en su contexto y de buscar una integración en la mirada de la ingeniería respecto a los componentes naturales y sociales de una zona anegada. Finalmente, las comparaciones antes hechas son útiles para corroborar el diagnóstico que años después hizo el ingeniero Agustín Díaz, es decir, la falta de concordancia formal, en este caso de tres planos hidrográficos.

Para terminar este ensayo, haré una valoración final del plano de Garay. Es incuestionable su calidad formal: la excelente factura; la facilidad para entender el motivo principal que es la obra de desagüe (un dique); la organización de los elementos que componen la carta donde ninguno atropella o distrae al otro (título, fecha, créditos, escalas, orientaciones, firma, entre otros); la buena composición que ubica al dique al centro y destacado; el equilibrio en las formas que se aprecia en la decisión del ingeniero de figurar completo el cerro de la Estrella cuando éste es sólo una referencia y no un motivo central para la comprensión de la temática principal, es decir, hubiera bastado la referencia de las curvas de nivel en las faldas de la eminencia para señalar uno de los extremos del dique, no obstante, la representación completa de este cerro ofrece un componente armonioso y atractivo para la carta, además de definir por completo y de una vez el contexto topográfico del área; el color, por último, es meritorio en dos sentidos, en el descriptivo y en el que le otorga al objeto mayor calidad visual. En síntesis, podemos calificar este trabajo de Garay como un plano sobrado, ${ }^{\text {Is }}$ donde el ingeniero se permite un lucimiento que no encontraremos una vez que se normalice el dibujo en el género; pero hay que precisar que la cualidad garbosa de la carta está dentro de los parámetros de la cartografía decimonónica, es decir, conserva la especificidad y naturaleza para ser reconocido y estudiado como un plano.

Sería complicado hacer una valoración similar en cuanto a sus características científicas, es decir, habría que conocer la posición geográfica de los asentamientos humanos que consigna (como por ejemplo Culhuacán y Mexi-

15. Agradezco a Hugo Arciniega esta observación. 
calcingo) o de una referencia natural que permanece inalterable en el terreno como lo es el cerro de la Estrella, y a partir de ellos medir la ubicación que hace de sitios secundarios como Taxqueña o la actual calzada de Tlalpan. A partir de esos datos y esas medidas, se podría conocer con rigor la veracidad de aquello que representa Garay. No obstante, no se puede perder de vista que este plano tiene un objetivo muy concreto: las obras de desagüe y su contexto, y que sólo más adelante se enlistarán las posiciones geográficas de varias ciudades y poblaciones, mismas que los ingenieros utilizarán como base para elaborar sus planos, o bien, reutilizarán otras cartas ya oficiales y sobre ellas trazarán proyectos o adicionarán a ellas lo construido.

\section{Consideraciones finales}

Es importante recordar uno de los argumentos centrales de Svetlana Alpers cuando se refiere a la cartografía: los mapas están imbuidos en un aura como fuente de conocimiento, sin atender a su exactitud. ${ }^{16}$ Existe una supuesta práctica científica que los respalda y, ubicados en este entendimiento, el contacto y la solicitud del investigador para con estos documentos serán siempre limitados. No obstante que este prejuicio está cimentado en la misma época de su aparición, es verdad que en el México del siglo xix el gremio de los ingenieros tuvo un gran poder y una presencia destacada en los ramos de la ciencia, la técnica y la política y que la práctica de la ingeniería expresó un prestigio social tan sólo igualado por la medicina y la abogacía. Los ingenieros podían ser calificados en su práctica profesional sólo por sus similares. Su trabajo, en especial los planos y mapas, denotaba su autoridad; particularmente ofrecían un tipo de reputación respaldado por la práctica que era poder; un ingeniero solía actuar sobre el territorio, lo medía, lo exploraba, lo transformaba y lo expresaba; lo traducía en datos o en imágenes.

Para entender las imágenes cartográficas producidas en México en el siglo XIX, es necesario penetrar en el ámbito particular de las ingenierías y en su intencionalidad, lo que significa recurrir a la arena política de la época, donde están los comitentes y de la que formaron parte los propios ingenieros.

I6. Svetlana Alpers, El arte de describir. El arte holandés en el siglo XVII, Madrid, Hermann Blume, 1987, p. 195. 
No es suficiente calificar (o descalificar) como científico o veraz un plano o mapa decimonónico, aun cuando su existencia se sustente en ese argumento. Se debe entender la importancia que tal premisa tenía en la época y establecer las otras propiedades igualmente válidas de las cartas, como lo es el valor simbólico de un producto de este género.

Por otro lado, la comunicación de los planos con otros medios de figuración del territorio es igualmente importante. Si las imágenes cartográficas decimonónicas eran obras de poder y de prestigio, debieron estar enlazadas con otras formas de representación, como la pintura, en su forma de apreciación, reconocimiento y conocimiento (aparente o realmente científica) del territorio, tarea todavía pendiente.

Para finalizar, puntualizaré otros aspectos que derivaron de este ensayo y que requieren, cada uno, un estudio más profundo:

I. Las formas y los diseños con que se expresó la información en la cartografía decimonónica en México no estuvieron estandarizados por lo menos hasta finales de la década de los setenta, lo que pudo originarse en la disimilitud en la formación académica de los ingenieros, o bien, en la decisión personal de cada uno en el momento de la presentación de sus trabajos. En ambos casos, es necesario indagar y hacer un seguimiento de estas premisas. Sabemos que hacia la década de los sesenta había varias ingenierías que incluían en sus planes de estudio el adiestramiento cartográfico; se impartían cursos de esta materia en la Academia de San Carlos, el Colegio de Minería, el Colegio Militar y la Escuela de Agricultura. Para todos los casos, la cartografía era un recurso instrumental.

No obstante la disimilitud en la forma, hay que atender a ciertos elementos más o menos constantes para poder comprender y leer este tipo de documentos; tales son el formato, la consignación del título, los créditos personales e institucionales, la escala y las orientaciones; $y$, en otro nivel más agudo, hay que observar la forma en que se figura el motivo central de la carta y la información complementaria, esto es, los accidentes de terreno, la ubicación y tipología de los asentamientos humanos con sus respectivas referencias arquitectónicas destacadas, los límites del terreno representado y, sobre todo, el registro o proyección de obras constructivas que muy comúnmente son el motivo de la cartografía decimonónica.

2. La situación natural de la cuenca de México hizo que las representaciones cartográficas tuvieran una importancia, uso y vitalidad particularmen- 
te importante (de forma especial las cartas de ingeniería hidráulica). Por otro lado, la exigencia de la época relativa al impulso del conocimiento del territorio en calidad de valoración nacional y la proliferación constructiva de infraestructura en transporte y comunicación son hechos que pusieron en la arena pública la exaltación de este tipo de representaciones del territorio.

3. La relación de los ingenieros con las instituciones que requieren la expresión cartográfica para primero conocer y luego actuar sobre el territorio, de donde se deriva la cartografía como un instrumento de comprensión (y de un tipo de asimilación) del espacio. Resulta sugerente proponer que la cartografía mexicana decimonónica es un objeto que, al plantear una organización del territorio y una visualización del mismo, es asimilada por los demás como una imagen del Estado. En otros países, la cartografía hecha por instancias particulares fue la que operó en la sociedad; aquí está por estudiarse el papel de la Sociedad Mexicana de Geografía y Estadística en esta historia, aunque de antemano sabemos que tuvo importantes subvenciones del Estado. ¿Cómo se consumieron estas representaciones del espacio en un ámbito más cotidiano? Sabemos de la circulación de planos, cartas, croquis y mapas en medios públicos, como en la prensa en las últimas décadas del siglo XIX, ${ }^{17}$ pero es preciso hacer un seguimiento a fondo de esto, así como de la relación de estas imágenes con las vistas y los paisajes publicados en los mismos medios.

4. La cartografía es una representación del territorio que puede dar una perspectiva que otros soportes no pueden ofrecer, como ocurre en el tema de las inundaciones. De igual modo, puede apoyar y ahondar en sugerencias que dan otros medios gráficos, como la pintura, en referencia a la cotidianidad de la población con los lagos, los canales, los ríos, los brazos, las vertientes, entre otros. Se propone una mirada atenta a las convenciones pictóricas de representación de terrenos anegados o con cantidades de agua variables y a la elección de los colores en estas temáticas; ahí podremos apreciar claramente la cercanía entre las formas cartográficas y pictóricas. A partir del conocimiento cartográfico es posible considerar algunas vistas por sus valores topográficos, hidrográficos, geológicos, orográficos, entre otros. Este saber da la ocasión

I7. Un par de ejemplos de cartografía publicada en la prensa están en La Patria Ilustrada, 30 de enero de I888, p. 60, y I2 de marzo de I888, p. I32. 
DOI: http://dx.doi.org/10.22201/iie.18703062e.2011.98.2363

LA INUNDACIÓN EN EL SUR DE LA CUENCA DE MÉXICO I 35

de apreciar otras posibilidades del paisaje decimonónico, ya se encuentre como protagonista o como motivo secundario.

En síntesis, la imagen cartográfica desempeña diferentes papeles: noción de escenario, percepción de un sitio, modelo de un territorio, figura de la geografía, interpretación del mundo... en fin, es un digno objeto de análisis e inspiración para el conocimiento. La voz de Svetlana Alpers sintetiza con lucidez las posibilidades en que se ubica la cartografía: "La imagen bajo la que la historia se presenta a nuestra vista es la de la descripción ilustrada de un lugar, y no la del drama de las vicisitudes humanas". ${ }^{8}$ is

18. Alpers, op. cit., p. 229.

N.B. Expreso mi gratitud a Fausto Ramírez, Fernando Aguayo, Peter Krieger y Hugo Arciniega, quienes enriquecieron este ensayo con sus comentarios y observaciones. También agradezco a mis compañeros de los seminarios: Arte del Siglo xix en México y Arquitectura del Siglo xix, del Posgrado en Historia del Arte de la Facultad de Filosofía y Letras, Universidad Nacional Autónoma de México.

* Artículo recibido el I3 de enero de 20 I; aceptado el 24 de marzo de 20 I. 